\title{
O mais importante da educação importante
}

\author{
The most important aspect of important education
}

DEMO, Pedro. O mais importante da educação importante. São Paulo: Atlas, $2012,168 p$.

Acir Mario Karwoski* Universidade Federal do Triângulo Mineiro

Regina Lima**

Universidade Federal do Triângulo Mineiro

Um dos mais recentes livros de Pedro Demo, intitulado $O$ mais importante da educaşão importante, foi publicado pela Editora Atlas em 2012, e contém 168 páginas divididas em quatro capítulos, conclusão, apêndice (com as tabelas utilizadas pelo autor no decorrer da obra) e referências bibliográficas.

O autor é graduado em Filosofia e doutor em Sociologia; professor titular aposentado e professor emérito da Universidade de Brasília (UnB). Em sua vasta vida de pesquisador e pensador, concentrou seus estudos nas questões mais críticas da educação e, nesta obra O mais importante da educação importante, diz que a inspiração para escrever o livro teve como ponto de partida um texto de comentários escrito por Demo em 2011 a fim de analisar o último Plano Nacional de Educação - PNE (2011-2020).

Já, na introdução, Demo traz críticas ao PNE enfatizando que, para ele, o que ficou constatado através dos dados extraídos é a necessidade de desconstruir radicalmente o sistema educacional atual para, em seguida, reconstruir outro sistema sustentado no direito de a criança aprender bem e com qualidade. $\mathrm{O}$ autor faz questão de ressaltar que o livro reflete suas experiências educacionais pelo país na busca por melhores condições de aprendizado dos alunos. E, esse aprendizado será mais efetivo se houver investimento na formação do professor.

No primeiro capítulo, Diagnóstico introdutório, o autor faz um panorama da educação atual, apontando falhas e indicando a necessidade de uma mudança drástica do sistema. Inicia suas reflexões com uma tabela, mostrando que, entre 1995 a 2009, a média de proficiência em Língua Portuguesa e em Matemática na Educação Básica seguiu uma tendência de queda constante e de recuperação lentíssima. Na seqüência, o autor põe na berlinda as práticas pedagógicas atuais, utilizando-se de vários exemplos para fazer o leitor repensar os modos de aquisição e transmissão do conhecimento. Trata de problemas tais como: a baixa escolaridade do professor da educação fundamental; as taxas elevadíssimas de reprovação; as principais dificuldades na alfabetização; a falta de professores em áreas sensíveis 
como ciências (Física, Química, Biologia e Matemática) e, encerrando o capítulo, questiona a formação inicial e continuada de professores bem como o sistema universitário.

No segundo capítulo, Questionando o sistema, o autor utiliza alguns pontos de partida dos quais elabora seus argumentos. O primeiro é o problema da gestão democrática. Demo faz a seguinte pergunta: "Se o aluno aprende tão mal, gerimos o quê?" (p. 21). O autor questiona a gestão democrática defendida pelo Ministério da Educação (MEC). Degundo o autor, o MEC pretende direcionar a democracia em seu favor; e alerta o leitor no sentido de que para existir uma gestão democrática coerente é preciso virar a mesa a fim de gerir oportunidades de vida. Em relação à formação docente, aponta vários problemas como ausência de qualidade, reação contrária dos pedagogos aos ambientes virtuais de aprendizagem (AVA), falta de valorização do professor e formação continuada sem qualidade. Para Demo, a reação contrária das pedagogias em relação aos ambientes virtuais só aumenta ainda mais o seu atraso. $\mathrm{O}$ autor deixa claro que a seleção negativa, os baixos salários, a formação deficiente e as péssimas condições de trabalho fazem da profissão um lugar de profissionais sofridos e sofríveis. No campo das novas tecnologias, o autor afirma que o professor precisa entender que é possível aprender bem em plataformas virtuais; e dá exemplos de como as novas tecnologias podem ser inseridas na educação.

O terceiro capítulo intitulado $O$ mais importante, Demo dialoga sobre o que considera"mais importante" na educação com a finalidade de apontar desafios. Para tanto, enfatiza dois pontos de partida: a) o mais importante em educação é o aluno aprender bem; e b) aluno aprende bem com professor que aprende bem (p. 56- 61). No primeiro ponto, diz que aprender bem inclui educação não formal ao lado da formal pois, segundo o autor, aprende-se até por meio de videogames; e aula instrucionista não deve ser um procedimento decisivo de aprendizagem. Para Demo, até hoje não existe um sistema de aprendizagem e sim um sistema de mero ensino (p. 59). Utiliza como exemplo a Singapura, que adotou o lema "ensine menos, aprenda mais" (p. 59). Diz ainda, que na escola o aluno não deve aprender apenas os conteúdos mas, principalmente, aprender habilidades de autoria e autonomia que servirão para a vida toda (p. 59). E completa dizendo que não devemos ser radicais para acabar com a aula mas com seu monopólio e, principalmente, com seu espírito instrucionista já que a aula deve servir para instigar a pesquisa e não para entupir aluno (p. 60). No segundo ponto, Demo faz uma reflexão sobre formação de professores; cita alguns dados e fala da condição marginalizada dos professores. Diz que é um equívoco colocar a culpa do fracasso da educação no professor, já que eles, os professores, apenas reproduzem o que aprenderam na universidade. Para o autor, a escola deve ser lugar de aprendizagem tanto do aluno como do professor e aponta como exemplo a Finlândia. Naquele país, o professor tem uma parte do seu tempo de trabalho reservado para estudos. $\mathrm{O}$ autor traça rumos a uma nova formação original e permanente para os professores e completa dizendo que somente universidades de pesquisa focadas no compromisso com o estudo e a pesquisa deveriam oferecer cursos de pedagogia 
e de licenciaturas. Ao falar da formação permanente, Demo diz que o estudo deve ser parte essencial do docente e os municípios devem ter o compromisso de desenvolver centros de formação permanente. Esses centros ofereceriam cursos mais aprofundados, nos quais os professores seriam instigados a pesquisar a fim de aperfeiçoar sua condição de autoria e de pesquisador profissional, buscando tornarse um professor-pesquisador.

Ainda, no decorrer do terceiro capítulo, ao falar das novas tecnologias, Demo recomenda que o professor encaixe a aprendizagem em plataformas virtuais a fim de aprimorá-la cada vez mais; aponta vários desafios para o ensino de Matemática e Ciências e defende uma Universidade que desenvolva nos alunos em formação inicial a postura de estudar, pesquisar, elaborar e argumentar.

O quarto capítulo intitulado Três tópicos exemplares possui característica prescritiva já que o autor discorre acerca de três tópicos que considera fundamentais para a transformação educacional. No primeiro tópico "Avaliação processual e problematização", Demo questiona as avaliações oficiais e aponta que a avaliação processual é mais eficiente, já que está mais próxima do dia-a-dia do aluno; diz que a avaliação processual é aquela conduzida no interior do processo de aprendizagem como parte integrante dele (p. 95). Na avaliação processual, o professor acompanha o aluno o tempo todo, descobrindo problemas de aprendizado que são contornados evitando assim a reprovação. Em "pedagogia da problematização", o autor diz que a ideia é transformar tópicos curriculares em problemas que os alunos irão resolver sob orientação docente; esses problemas devem ser reais e fazer parte da vida do estudante. Para Demo, com a pedagogia da problematização, o aluno aprende a estudar, pesquisar, elaborar, argumentar e a contra-argumentar numa atitude de desconstrução e reconstrução (p. 98). No tópico "Escolas de Tempo Integral (ETI)", Demo discute a importância da proposta desde que a proposta envolva renovação pedagógica. Diz que, hoje, a ETI funciona apenas como escola comum com maior tempo de duração. Para o autor, o que vai fazer a Escola de Tempo Integral ser diferente é preparar melhor o professor com formação continuada de qualidade, salários diferenciados e professores com dedicação exclusiva ao projeto pedagógico daquela ETI. Uma escola que se interesse por cultura, esporte, higiene, saúde, ambiente comunitário, atualizada tecnologicamente e o mais importante: trabalhe a fim de que o aluno aprenda bem. Ainda, no decorrer do capítulo, o autor argumenta que, na ETI, o maior desafio deve ser o pedagógico pois todas as atividades devem ter como objetivo a aprendizagem. As aulas instrucionistas sejam abandonadas e dando lugar ao tempo de estudo com a resolução de problemas; $\mathrm{e}$ professores que proponham desafios cada vez mais abrangentes. Na ETI, não se deve adotar teoria específica pois cada professor deve reconstruir sua proposta e sua prática. As disciplinas não devem ser isoladas; misturando as disciplinas, torna-se possível organizar problematizações desafiadoras interdisciplinares. A organização do tempo deve ser flexível com alunos aprendendo de maneira participativa e reconstrutiva. Para Demo, o maior desafio da ETI é o professor pois, para que o aluno tenha um ambiente renovado e inovador, o aluno precisa de um professor renovado e inovador (p. 116). No terceiro e último tópico, desse quarto capítulo "Ambientes Virtuais de Aprendizagem", Demo defende o uso das tecnologias na 
escola como algo imprescindível. Aponta algumas mudanças tais como: superar o determinismo tecnológico; usar plataformas autorais de maneira crítica e criativa; fomentar a produção de textos multimodais; transformar o aluno passivo em pesquisador e buscar motivações próprias da nova geração.

Demo encerra o livro reconhecendo sua limitação em cobrir todos os problemas que abarcam a educação e diz que intenção nessa obra é construir um referencial que indique a necessidade de uma mudança radical na educação brasileira. Diz ainda que temos um compromisso com o futuro das novas gerações. E apesar dos esforços do Ministério da Educação (MEC) e de muitas secretarias estaduais e municipais de educação, o sistema educacional não tem avançado muito no sentido de melhorar.

Demo busca, o tempo todo, orientar o leitor no sentido de que, para ocorrer melhoria efetiva na educação, será necessário investir na valorização do professor uma vez que somente com um professor competente podemos garantir o direito de o aluno aprender bem. O livro é um bom referencial para educadores porque, além de expor os diversos problemas que perpassam a educação na atualidade, traz reflexões relevantes para o processo de ensino-aprendizagem, assinala caminhos para superar as carências relacionadas às instituições de ensino, à gestão do conhecimento e ao desempenho do professor.

Em linguagem acessível, a obra $O$ mais importante da educação importante traz contribuições valiosas para se pensar os problemas educacionais. Suge alternativas de ação para que as dificuldades possam ser minimizadas. Nesse sentido, a obra é indicada como subsídio importante para professores, gestores educacionais, diretores de escolas, secretários de educação e para os ocupantes de cargos públicos (legislativo e executivo) que definem e aprovam as metas e estratégias para o Plano Nacional de Educação - PNE.

* Professor Doutor da Universidade Federal do Triângulo Mineiro, Curso de Letras. Uberaba, Minas Gerais - Brasil.

** Graduada em Letras. Especialização em Crítica Literária e Ensino de Literatura. Técnica em Assuntos Educacionais na Pró-Reitoria de Ensino da Universidade Federal do Triângulo Mineiro - UFTM. Uberaba, Minas Gerais - Brasil.

\section{Correspondência}

Acir Mario Karwoski - Avenida Frei Paulino, 30 - CEA/UFTM, Abadia, CEP: 38025-180 - Uberaba, Minas Gerais - Brasil.

E-mail: acirmario@gmail.com - regina.lima@proens.uftm.edu.br

Recebido em 19 de janeiro de 2013

Aprovado em 23 de agosto de 2013 